\title{
Editorial: embedded foundations under complex loading
}

On behalf of my co-editors I would like to welcome you to this themed issue of Géotechnique based around the performance of foundations under complex loading. The call for papers was inspired by the increasing interest in modern infrastructure developments that face a challenging loading environment. Examples include the installation of large numbers of wind turbines (both onshore and offshore) and the demand for fully earthquake-resistant foundations, where Géotechnique has already published many contributions on these topics. These challenges have led to new research and innovative design solutions concerning the accurate prediction and modelling of capacity, stiffness and dynamic behaviour of foundations. Piles and caissons of unprecedented size are being contemplated and new installation technologies are being developed to safely sustain large, multi-component and often cyclic loads. These must be resisted while meeting long-term static and dynamic foundation performance requirements set by challenging structural specifications in harsh environments, such as for offshore wind developments. If you are interested in these themes you may like to have a look at other previous and current publications in Géotechnique such as those by Bienen et al. (2018), Liu et al. (2019), Lovera et al. (2020), Richards et al. (2019), Truong et al. (2019) and Zografou et al. (2019).

Turning back to this issue, the call attracted a wide range of abstracts (61) covering topics from suction caissons, monopiles, anchoring systems and seismic design. On the basis of the abstract submissions 30 papers were invited to be worked up into a full submission and 15 were received. Out of these, eight made it through the Géotechnique review process and six are contained herein. Two additional papers have been accepted but, due to space limitations, are unfortunately not included in this issue and will appear as individual papers in Géotechnique (Kementzetzidis et al., 2020; Mandolini et al., 2020); they are available online ahead of print on Géotechnique's Virtual Library homepage.

In this issue, the first paper, by Buckley et al. (2020), reflects a recent academic and industry focus on the performance of monopiles driven in chalk for offshore wind deployments. This themed issue call followed the 2018 British Geotechnical Association conference 'Engineering in Chalk', where authors from this paper presented a keynote paper on 'Behaviour of piles driven in chalk' that introduced the 'Chalk ICP-18' concept for pile design (Jardine et al., 2018). The paper by Buckley et al. focuses on the analysis of the results from field testing and describes pile testing using a novel large offshore reaction system. These tests showed that piles in chalk may see significant reductions in resistance during driving - greater than predicted by Ciria C574 (Lord et al., 2002) - followed by very significant increases in axial capacity post installation. These final capacities were five to ten times those estimated by the Ciria C574 approach. The findings suggest a potentially significant opportunity for cost savings and efficiency improvements for monopiles installed in chalk. The Chalk ICP-18 design approach also gave a good overall representation of field capacity and with inclusion of shaft capacity expressions that include set-up, the potential to capture long term performance. In this case, the complexity of loading comes from the effects of installation on in-service behaviour and how the complexity of chalk affects the long-term in-service performance.

Continuing on the theme of offshore foundations but moving from field testing to the effects of varying constitutive models in numerical approaches, the paper by Jostad et al.
(2020) assesses the performance of varying approaches and their ability to represent the behaviour of soils subjected to complex and irregular loading over a wide range of strain levels. Four different soil models to describe the stress-strain relationships of dense sand are evaluated: two that follow the actual stress history within individual cycles and two that calculate accumulated strains as a function of numbers of load cycles. These models are evaluated on the basis of their theoretical framework and back-calculation of laboratory tests carried out for the design of foundations in dense sand. The authors conclude that models that follow the full stress history within every cycle remain poor at predicting accumulated strains over many cycles, even with calibration of their parameters. Models that only attempt to predict the accumulated strains are more reliable for this purpose, as demonstrated by calibration to laboratory tests. Two of the models are used to make comparative predictions of the accumulated movement of an offshore wind turbine foundation.

The paper by Georgiadis \& Sheil (2020) tackles an often-overlooked load combination: the effect of torsion in combination with lateral load on a pile. In the same way that we twist a cork to make it easier to pull from a bottle vertical-torsional combined loading - a torsional load can also reduce the lateral capacity of a pile. The authors use classical limit analysis to bound the combined torsionallateral ultimate capacities, through an upper bound failure mechanism and a lower bound stress field. They show that a torsional load can reduce the lateral capacity by up to $50 \%$ for full pile-soil adhesion, although the effect reduces with reducing adhesion. The results are distilled into a simplified equation for design purposes.

Moving away from the theme of piles, the paper by Gorini $\&$ Callisto (2020) tackles the challenges of seismic design analyses of bridge abutments. The authors develop a macro-element simplified representation of the dynamic response of the bridge to include in a finite-element model of the soil-abutment system which results in reduced computational cost. Comparison between the new simplified approach and full three-dimensional dynamic time-domain analyses of an idealised soil-bridge system, both featuring non-linear advanced soil constitutive models, demonstrates the capabilities and computational efficiency of the proposed approach in predicting maximum and residual foundation displacements and the magnitude of internal forces in the structure, which are key criteria in abutment design. The paper also provides a strategy for the calibration of the bridge macro-element in time-domain analyses making use of a limited number of input parameters.

The final two papers are concerned with the performance of offshore plate anchors, following the emerging interest in floating offshore energy devices, such as wind developments in deep water sites and tidal and wave energy generators. Although having some shared authorship, the papers look at the monotonic, cyclic and maintained loads in different soils: the first (Chow et al., 2020) in a more conventional sand and the second paper in a calcareous silt (Zhou et al., 2020). Having two papers in the same issue on the subject allows the direct comparison of anchor performance in different soil types and the differences in design that may result. The Chow et al. paper looks at a plate loaded at varying rates in dense sand, under both monotonic and irregular cyclic conditions. The authors found that the anchor's ultimate monotonic capacity in dense sand increased by up to $173 \%$ when moving from drained to undrained behaviour and in drained and 
undrained irregular cyclic loading the anchor capacity increased by up to $33 \%$, attributed to soil volume changes associated with cyclic densification. The main contribution of the paper is a framework based around the 'backbone curve' approach to quantify the capacity changes across the consolidation regime or varying rates of loading. It is also shown that the change from monotonic to cyclic loading produces similar anchor movement and loss of depth. In the paper by Zhou et al. (2020), the plate in silt also shows significant gains in capacity after consolidation under maintained loading. Combinations of maintained and cyclic loading gave further increases still, once the cyclically generated pore pressure is permitted to dissipate. The centrifuge results were matched well by the simulations using the Zhou et al. (2019) effective stress framework. The paper suggests that a less conservative basis for plate anchor design may be warranted, particularly if loading events are relatively predictable, for example, with offloading events for a taut moored floater. The outputs from the final two papers use centrifuge physical modelling in contrast to the previous papers on field testing and numerical approaches.

We would like to take this opportunity to thank all of the authors for their contributions and time invested in the submission and review process. The papers included in this issue reflect the range of themes seen in the abstracts and have extended outside the confines of classic embedded foundations to include bridge abutments and plate anchor performance as well.

Michael John Brown University of Dundee

Andrea Diambra University of Bristol

Mohamed Rouainia Newcastle University

David White University of Southampton

\section{REFERENCES}

Bienen, B., Klinkvort, R. T., O'Loughlin, C. D., Zhu, F. \& Byrne, B. W. (2018). Suction caissons in dense sand, part II: vertical cyclic loading into tension. Géotechnique 68, No. 11, 953-967, https://doi.org/10.1680/jgeot.16.P.282.

Buckley, R. M., Jardine, R. J., Kontoe, S., Barbosa, P. \& Schroeder, S. P. (2020). Full-scale observations of dynamic and static axial responses of offshore piles driven in chalk and tills. Géotechnique 70, No. 8, 657-681, https://doi.org/10.1680/jgeot. 19.TI.001.

Chow, S. H., Diambra, A., O'Loughlin, C. D., Gaudin, C. \& Randolph, M. F. (2020). Consolidation effects on monotonic and cyclic capacity of plate anchors in sand. Géotechnique $\mathbf{7 0}$, No. 8, 720-731, https://doi.org/10.1680/jgeot.19.TI.017.

Georgiadis, K. \& Sheil, B. (2020). Effect of torsion on the undrained limiting lateral resistance of piles in clay. Géotechnique 70, No. 8, 700-710, https://doi.org/10.1680/jgeot.19.TI.010.

Gorini, D. N. \& Callisto, L. (2020). A macro-element approach to analyse bridge abutments accounting for the dynamic behaviour of the superstructure. Géotechnique 70, No. 8, 711-719, https://doi.org/10.1680/jgeot.19.TI.012.

Jardine, R. J., Buckley, R. M., Kontoe, S., Barbosa, P. \& Schroeder, F. C. (2018). Behaviour of piles driven in chalk. In Engineering in chalk (eds J. A. Lawrence, M. Preene, U. L. Lawrence and R. Buckley), pp. 33-51, https://doi.org/ 10.1680/eiccf.64072.033. London, UK: ICE Publishing.

Jostad, H. P., Dahl, B. M., Page, A., Sivasithamparam, N. \& Sturm, H. (2020). Evaluation of soil models for improved design of offshore wind turbine foundations in dense sand. Géotechnique 70, No. 8, 682-699, https://doi.org/10.1680/jgeot. 19.TI.034.

Kementzetzidis, E., Metrikine, A. V., Versteijlen, W. G. \& Pisanò, F. (2020). Frequency effects in the dynamic lateral stiffness of monopiles in sand: insight from field tests and 3D FE modelling. Géotechnique, https://doi.org/10.1680/jgeot.19.TI.024.

Liu, Y., Abell, J. A., Diambra, A. \& Pisanò, F. (2019). Modelling the cyclic ratcheting of sands through memory-enhanced bounding surface plasticity. Géotechnique 69, No. 9, 783-800, https://doi.org/10.1680/jgeot.17.P.307.

Lord, J. A., Clayton, C. R. I. \& Mortimore, R. N. (2002). Engineering in chalk, Ciria C574. London, UK: Construction Industry Research and Information Association (Ciria).

Lovera, A., Ghabezloo, S., Sulem, J., Randolph, M. F., Kham, M. \& Palix E. (2020). Pile response to multi-directional lateral loading using $\mathrm{P}-\mathrm{y}$ curves approach. Géotechnique, https://doi.org/ 10.1680/jgeot.18.P.297.

Mandolini, A., Diambra, A. \& Ibraim E. (2020). Stiffness of granular soils under long-term multiaxial cyclic loading. Géotechnique, https://doi.org/10.1680/jgeot.19.TI.018.

Richards, I. A., Byrne, B. W. \& Houlsby, G. T. (2019). Monopile rotation under complex cyclic lateral loading in sand. Géotechnique, https://doi.org/10.1680/jgeot.18.P.302.

Truong, P., Lehane, B. M., Zania, V. \& Klinkvort, R. T. (2019). Empirical approach based on centrifuge testing for cyclic deformations of laterally loaded piles in sand. Géotechnique 69, No. 2, 133-145, https://doi.org/10.1680/jgeot. 17.P.203.

Zhou, Z., White, D. J. \& O'Loughlin, C. D. (2019). An effective stress framework for estimating penetration resistance accounting for changes in soil strength from maintained load, remoulding and reconsolidation. Géotechnique 69, No. 1, 57-71, https://doi.org/10.1680/jgeot.17.P.217.

Zhou, Z., O'Loughlin, D., White, D. J. \& Stanier, S. A. (2020) Improvements in plate anchor capacity due to cyclic and maintained loads combined with consolidation. Géotechnique 70, No. 8, 732-749. https://doi.org/10.1680/jgeot.19.TI.028.

Zografou, D., Gourvenec, S. \& O'Loughlin, C. D. (2019). Response of normally consolidated kaolin clay under irregular cyclic loading and comparison with predictions from the accumulation procedure. Géotechnique 69, No. 2, 106-121, https://doi.org/10. 1680/jgeot.16.P.340. 